Ana Dili Eğitimi Dergisi
Journal of Mother Tongue Education
ADED - JOMTE
www.anadiliegitimi.com

\title{
Yapılandırılmış Okuma Yönteminin Okuma Hızı, Doğru Okuma ve Sesli Okuma Prozodisi Üzerindeki Etkisi*
}

\author{
Hasan Kağan Keskin ${ }^{1}$ \\ Hayati Akyol ${ }^{2}$
}

\begin{abstract}
Özet
Bu çalışma ile yapılandırılmış okuma yönteminin, ilköğretim dördüncü sınıf öğrencilerinin, okuma hızı, doğru okuma ve prozodik okuma becerileri üzerindeki etkisinin araştıııması amaçlanmışır. Araştırma için 2010-2011 öğretim yılı bahar döneminde Afyonkarahisar merkeze bağlı dört ilköğretim okulundan veri toplanmıştır. Bu okullar arasından basit tesadüfi yöntemle belirlenen bir okuldaki akıcı okuma becerisini yeterince kazanamamış dokuz öğrenci ile oluşturulan grupta 24 ders saati "yapılandııımış okuma yöntemi" uygulanmıştır. Elde edilen bulgulara göre yapılandırılmış okuma yöntemi öğrencilerin okuma hızı, doğru okuma ve sesli okuma prozodisi becerileri üzerinde etkili olmuştur. Sonuç olarak, yapılandırıımış okuma yönteminin, akıcı okuma becerileri yönünden endişe düzeyinde olan öğrencilerin, bu becerilerini geliştirmede etkili olduğunu söylemek mümkündür.
\end{abstract}

Anahtar Sözcükler: akıcı okuma, hız, doğruluk, prozodi

\section{The Effect of Structured Reading Method on Reading Rate, Accurate Reading and Oral \\ Reading Prosody ${ }^{*}$}

\begin{abstract}
The aim of the present study is to investigate the effects of structured reading method on fourth graders with regard to reading rate, accurate reading and prosodic reading skills. Data were collected from four primary schools in Afyonkarahisar city center in 2011 Spring term. A school was randomly selected from these schools and a group comprising nine students with inadequate fluent reading skills was formed and a 24-hour "structured reading method" was applied to this group. The findings revealed that structured reading method was effective on students' reading rate, accurate reading and oral reading prosody. In conclusion, it could be argued that structured reading method is effective on developing students who have inadequate reading skills in terms of fluent reading skills.
\end{abstract}

Keywords: reading fluency, rate, accuracy, prosody.

\footnotetext{
* "Akıcı Okuma Yöntemlerinin Okuma Becerileri Üzerindeki Etkisi" isimli doktora tezinden üretilmiştir

* "This article has been produced within the scope of the doctoral dissertation "The effect of fluent reading methods on reading skills".

${ }^{1} Y r d . D o c ̧ . D r .$, Düzce Üniversitesi, Eğitim Fakültesi, İlköğretim Bölümü. Düzce. kagankeskin@yahoo.com

${ }^{2}$ Prof.Dr., Gazi Üniversitesi, Eğitim Fakültesi. Ankara. hakyol@gazi.edu.tr
} 


\section{Giriş}

Okuma; insan yaşamında doğal olmayan, ancak sonradan kazanılabilen, bireye bütün yaşamını etkileyebilecek nitelikte, sosyal, kültürel ve bilişsel alanlarda yeterlilik sağlayan oldukça karmaşık bir süreçtir. Karmaşık ve bir o kadar da dinamik olan bu süreç (Logan, 1997), okuyucunun ön bilgileri ile okunan metnin okuyucu tarafından yeniden yorumlanması sonucunda bir anlam kurma sürecine dönüşmektedir (Akyol, 2006). Bu anlam kurma süreci, bireyin yaşamı boyunca ona eşlik eden ve katkı sağlayan bir mekanizmadır. Bu mekanizmanın sağlıkı çalışması bireyin eğitim, sosyal ve kültürel hayatını olumlu yönde etkilemektedir. Bu nedenle son yıllarda okumanın nasıl olması gerektiği daha çok sorgulanmaya başlamıştır. Bu sorgulamalardan çıkan ortak sonuç ise okumanın akıcı (National Reading Panel, 2000); diğer bir tabirle konuşurcasına olması gerektiğidir (Akyol, 2006).

Akıcı okuma ile ilgili farklı tanımlamalar yapılmıştır. Harris ve Hodges'e (1995) göre akıcı okuma, anlamayı olumsuz etkileyebilecek kelime tanıma problemlerinden bağımsız olarak okuyabilmektir; otomatik olarak okumadır. National Reading Panel'in (2000) raporunda ise akıCı okuma; metni pratik, doğru ve düzgün vurgulamayla ifade edebilme yeteneğidir. Zutell ve Rasinski'ye (1991) göre akıcı okuma, kelime tanımaya fazla çaba sarfetmeden otomatik olarak, cümle içindeki anlam ünitelerine dikkat ederek, tonlamaları, vurgulamaları gereken yerlerde doğru uygulayarak yazarın heyecanını ve duygularını, okuma işine yansıtarak yapılan okumadır. Akyol (2006) ise akıcı okumayı, noktalama işaretleri, vurgu ve tonlamalara dikkat edilen, geriye dönüş ve kelime tekrarına yer verilmeyen, heceleme ve gereksiz duruşlar yapılmayan, anlam ünitelerine dikkat edilerek, konuşurcasına yapılan okuma olarak ifade etmektedir.

Yukarıdaki tanımlardan da anlaşılacağı üzere akıcı okuma hakkında ortak bir tanıma ulaşılamamıştır. Akıcı okumanın tanımı yapılırken onun ilişkili olduğu becerileri ifade edebilen kavramlar üzerinden tanımlamalar yapılmıştır. Bunlar; otomatikleşme, işlem hızı, okuma hızı, kelime tanıma hızı veya kelime tanımada beceriklilik gibi kavramlardır (Wolf ve Katzir-Cohen, 2001). Ancak, akıcı okumanın birden fazla becerinin aynı anda işe koşulmasıyla gerçekleştiği, okuma alıştırmaları ile gelişebildiği, otomatik kelime tanıma, kelimeleri doğru okuma ve prozodik özellikleri etkin bir şekilde ortaya koyma davranışlarını kapsaması gerektiği konusunda bir çok araştırmacı hem fikirdir (Akyol, 2006; Hudson, Lane ve Pullen, 2005; Kuhn, Schwanenflugel, Meisinger, Levy ve Rasinski, 2010; Rashotte ve Torgesen, 1985; Samuels, 2006b; Schrauben, 2010; Schreiber, 1991; Wolf ve KatzirCohen, 2001). Bu tanımlardan hareketle akıcı okumanın, yeterli düzeyde kazanılmış okuma hızı, doğru okuma ve prozodik özelliklerin birlikte ve uyum içerisinde çalışmasıyla gözlenebilen bir okuma becerisi olduğu ileri sürülebilir.

Okuma hızı akıcı okumada oldukça önemlidir. Aynı zamanda akıcı okuma çalışmalarında da sıkıkla ölçülen bir beceridir. Öğrencinin okuma hızını ilerletmesi kelimeleri doğru okumasına bağııdır. 
Çünkü doğru okuma becerisi anlama için oldukça önemli bir akıcı okuma bileşenidir ve okuma hızını doğrudan etkileyebilmektedir. Okuma hızı tekrarlı okumalar sayesinde ilerleyebilmektedir Okuma hızının artması ile de okumada otomatiklik görülmeye başlanır. Yani okuma işi artık daha otomatik bir aşamaya geçmektedir (Samuels, 1979). Genel olarak otomatiklik, fazla çaba gerektirmeden, hızlıca yapılan bir işi ifade etmekte kullanılan bir terimdir (Deeney, 2010). Otomatik olarak kazanılan bir beceri kendi içinde "belli bir hızı" ihtiva eder.

Otomatikleşmenin temelinde, "ilk başlarda yoğun olarak beceriye odaklanan dikkatin, bilişsel enerjinin büyük bir bölümünü tükettiği” mantığı yatmaktadır. Beceri kazanıldıktan sonra artık ilk başta tüketilen bilişsel enerjiye ihtiyacın azalmasıdır. Bunun en önemli nedeni kazanılmak istenen becerinin tekrarlar sayesinde otomatikleşmesi ve bilişsel enerjinin diğer alanlara yönelmesidir (Samuels, 1979). Stahl ve Kuhn'a (2002) göre ise otomatikleşme becerisi aslında kelimeyi tanıma ve aynı anda onun anlamı ile ilişki kurabilmektir. Sonuç olarak, kazanılan hız sayesinde otomatikleşen okuma becerisi birey için daha nitelikli okuma-anlama süreci demektir.

Bu sürece etki eden bir diğer unsur ise metni doğru okumaktır. Yani metin hem doğru hem de otomatik bir şekilde okunmalıdır. Çünkü doğru anlam kurmak için doğru okumak şarttır. Diğer bir ifadeyle metni doğru okuyamayan öğrencinin metinden anlam kurması oldukça zordur. Çünkü dikkatinin çoğunu metni doğru okuyabilmeye verdiğinden okuma hızı da yavaşlamaktadır (National Reading Panel, 2000; Samuels, 1979, 2006b). Okumanın gelişim basamaklarına bakıldığında en temel öğrenci-harf etkileşiminin ses düzeyinde kurulduğu görülebilir. Yani, öğrenci harfleri isim olarak değil ses olarak öğrenmektedir. Akyol'a (2007) göre bu süreçte sesler, harflerin sembollerinden önce işitsel ve görsel uyaranlar yoluyla öğrencilere verilmelidir. Sesli harfler doğrudan verildiği için öğrenilmesi daha kolaydır. Daha sonra verilen sessiz harfler sesli harflerin önüne veya arkasına getirilmek suretiyle yeni sesler elde edilmeye başlanır. Aslında bu aşamada "doğru okuma"nın temelleri atılmaktadır. Daha sonra yapılacak olan okuma etkinlikleri, birden fazla harfin yan yana getirilerek elde edilmesinden oluşan harf kombinasyonları üzerinden yürütülmektedir. Yan yana getirilen bu harf-ses örüntüleri bir anlam ifade etmelidir. Ancak, yeni başlayan bir öğrenci için okumanın bu dönemi harflerin seslendirilmesidir. Harflerin, dolayısıyla da kelimelerin doğru seslendirilmesi akıcı okumanın en temel bileşenidir. Burada kazanılan doğru okuma becerisi, otomatikleşme sürecine geçişi sorunsuz başlatma açısından önemlidir. Hızlı kelime tanıma ve doğru okuma becerisinin kazanılması aynı zamanda akıcı okuma becerisini de geliştirir (Chall, Jacobs ve Baldwin, 1991). Diğer bir ifadeyle, doğru okuma becerisi, akıcı okuma becerisinin ön şartlarından birisidir (Samuels, 2006a). Doğru okuma becerisini kazanma, otomatik olarak sürdürebilme, prozodik özellikleri okumada kullanabilme ve aynı anda okunan metni anlama akıcı okumanın özünü teşkil etmektedir.

Çocuklar okumayı öğrenmeden önce kendi dillerinde bir takım kelimeleri bilmektedirler. Konuşma dilinde bilinen kelimelerin yazı dilinde de öğrenilmesi kelime tanıma becerisi açısından kritik 
bir dönemdir (A. J. Harris ve Sipay, 1990). Bu beceri kazanılmadan akıcı okumanın gerçekleşmesi imkânsızdır. Öğrenciler okumayı öğrendikten sonra aşina oldukları kelimeleri bir bakışta okuyabilirken, aşina olmadıkları bir kelimeyi yavaş bir şekilde ve çözümleyerek okumaktadırlar (Ehri ve McCormick, 1998). Ayrıca okuyucular, doğru okuma becerilerini etkili bir şekilde kullanabilmeleri için zengin bir kelime hazinesine de ihtiyaç duyarlar (Hudson ve diğerleri, 2005). Kelime hazinesi ise öğrencilerin hem anlama hem de anlatım becerilerini doğrudan etkilemektedir (Özbay ve Melanlıoğlu, 2008).

Kelimenin doğru olarak seslendirilmesi tek başına yeterli değildir. Aynı zamanda kelimenin okuyucu tarafından ayırt edilmesi gerekir. Kelimeyi ayırt etme ise kelimeyi doğru anlamayı gerektirir (Akyol, 2006). Bu beceri okuyucunun metinden anlam elde etme sürecine doğrudan etki etmekte ve akıcı okumanın niteliği noktasında belirleyici olmaktadır. Yanlış okunan ve ayırt edilemeyen kelimeler okuyucunun okuma amacı dışında anlam oluşturmasına neden olmaktadır (Deeney, 2010; Hudson ve diğerleri, 2005).

Akıcı okumadaki bir diğer unsur ise prozodidir. Prozodi; tonlama, vurgulama ve zamanlamayı içerir. Bu özelliklerin okuma işine yansıtılması da "prozodik okuma" olarak adlandırılır ve dilin kendine özgü melodisi sesli okumada hissedilir. Prozodik okuma aynı zamanda cümleyi uygun yerlerinden anlam ünitelerine bölmeyi de gerektirir. Anlam üniteleri dil içerisinde önemli bir role sahiptir ve dile anlaşılırık kazandııır (Dowhower, 1991; Schreiber, 1991; Yıldız, Yıldııım, Ateş ve Çetinkaya, 2009). Prozodi olmadan metin, ifade etme gücü açısından yetersiz ve monotondur. Bu durum akıcı okuyabilen ve okuyamayan öğrencileri ayırma noktasında da belirleyicidir (Zutell, Donelson, Bevans ve Todt, 2006). Bu belirleyicilik okunanın dinlenilmesi yoluyla kolaylıkla hissedilir.

Akıcı okuma becerisini yeterince kazanamamış öğrenciler için yukarıda sayılan becerileri geliştirmeye yönelik farklı yöntemler uygulanmaktadır. Tekrarlı okuma, koro okuma ve eşli okuma yöntemleri en çok kullanılan yöntemlerdir. Ancak son yıllarda sadece bir yöntemin uygulanması yerine farklı yöntemlerin bir araya getirilmesi ile oluşturulan daha geniş kapsamlı yöntemler (Kuhn, 2005; Morrow, Kuhn ve Schwanenflugel, 2006; Rasinski, 2010; Schwanenflugel ve diğerleri, 2009) geliştirilmiştir. Bu nedenle bu çalışma için de prozodik modelleme ve anlam üniteleri ile okumayı esas alan bir yöntem yapılandırılmıştır. Yapılandırılan bu yöntem ile okuma becerisi yeterince gelişmemiş ilköğretim dördüncü sınıf öğrencilerinin okuma hızı, doğru okuma ve prozodik okuma becerileri üzerindeki etkisinin ne olduğunun belirlenmesi amaçlanmıştır.

\section{Yöntem}

$\mathrm{Bu}$ araştırma, yapılandııımış akıcı okuma yönteminin öğrencilerin akıcı okuma becerileri üzerindeki etkisini belirlemeye yönelik olduğu için deneyseldir. Deneysel desenlerden tek gruplu desen kullanılmıştır (Cohen, Manion ve Morrison, 2007). 


\section{Evren ve Örneklem}

Araştırmanın çalışma evrenini, 2010-2011 öğretim yılında Afyonkarahisar ili Merkez ilçeye bağlı 98 Illköğretim Okulunda öğrenim gören dördüncü sınıf öğrencileri oluşturmaktadır. Örneklem belirleme süreci iki aşamada yürütülmüştür. İlk aşamada, kolay örnekleme yolu ile çalışma yapılacak okullar belirlenmiştir. Kolay örnekleme, yapısı gereği araştırmacıya istediği veriye daha çabuk ulaşabilme ve ekonomiklik sağlamaktadır (Cohen ve diğerleri, 2007). Bu amaçla, Afyonkarahisar il merkezindeki Okul A, Okul B, Okul C ve Okul D İlköğretim okulları örneklem seçimi çalışmasına dâhil edilmiştir. Okulların seçiminde, bulundukları yerleşim yerlerindeki sosyo-kültürel ve ekonomik yapı ile okulların başarı düzeyinin birbirine yakın olmasına dikkat edilmiştir.

ikinci aşamada ise, amaçlı örnekleme yolu ile söz konusu okullardan öğrenciler belirlenmiştir. Amaçlı örnekleme, araştırmanın amacına en uygun olanların araştırmaya dâhil edilmesine imkân verir. Araştırmacı tarafından, önceden belirlenen ölçütleri ve nitelikleri karşılayan kitlenin alınmasını gerektirir. Amaçlı örneklemenin, olasılıklı örnekleme yöntemlerinden küçük bir üstünlüğü de, "çok özel nitelik taşıyan durumlara" odaklanabilmesidir. Bu durum, olasılıkı örnekleme yöntemleri ile her zaman mümkün olmamaktadır (Cohen ve diğerleri, 2007). Bu araştırmada da özel bir grup hedeflendiğinden amaçlı örnekleme yönteminin bu araştırmanın ihtiyacına cevap verebileceği düşünülmüştür.

Amaçlı örnekleme gereği, söz konusu okulların dördüncü sınıflarında öğrenim gören 172 öğrenci üzerinde, okuma hızı, doğru okuma ve prozodik okuma becerilerini ölçmeye yönelik çalışmalar yürütülmüştür. Okuma hızını belirlemeye yönelik, öğrencilerin Türkçe derslerinde kullanmadığı bir dördüncü sınıf Türkçe ders kitabından (Çanakçı, Özaykut, Taşdemir, Yardımcı ve Yetimoğlu, 2008) seçilen okuma parçası her öğrenciye, yaklaşık 2 dakika sesli olarak okutulmuş ve bu süreç görüntülü olarak kayıt altına alınmıştır. Bu kayıtlar analiz edilerek, öğrencinin, bir dakikada okuduğu doğru kelime sayısı ile doğru okuma yüzdeleri hesaplanmıştır. Keskin ve Baştuğ (2011) tarafından geliştirilen "Prozodik Okuma Ölçeği" ile de öğrencilerin, sesli okuma prozodi düzeyleri belirlenmiştir.

Elde edilen veriler işlenerek, doğru okuma becerisinden alınan puanlara göre, ölçme araçları tarafından kabul edilen "yetersiz veya endişe düzeyi" kapsamına giren 51 öğrenci araştırmanın örneklemine dâhil edilmiştir. Hedeflenen düzeydeki öğrenci sayısının az olması nedeniyle Okul D öğrencileri örneklemden çıkarılmıştır. Nihai olarak öğrencilerin okullara dağılımı Okul A ( $n=21)$, Okul B $(n=9)$, ve Okul $C(n=9)$ şeklindedir. Belirlenen okullardan basit tesadüfi yöntemle seçim yapılmış ve Okul B'de yapılandırılmış okuma yönteminin uygulanmasına karar verilmiştir. 


\section{Uygulama}

Yapılandırılmış okuma: Çalışma öncesi araştırmacı tarafından Milli Eğitim Bakanlığı, Eğitim Teknolojileri Genel Müdürlüğü’nün (Milli Eğitim Bakanlığı, 2011) hazırlamış olduğu, 100 Temel Eserin tanıtımına yönelik sesli kitap bölümleri internet üzerinden dinlenerek yazıya aktarılmış ve 100-200 kelimelik metinler oluşturulmuştur. Bu metinlerdeki noktalama işaretleri araştırmacı tarafından kaldırılmıştır. Çalışmalarda bir dizüstü bilgisayar ve harici hoparlör kullanılmıştır. İlk önce metinler öğrencilere bilgisayar ortamında iki defa dinletilmiş ve sonraki dinlemede cümledeki anlam gruplarına göre kesme işareti "/" ile metin üzerine işaretlemeler yapılmıştır. Bu işaretleme sırasında metin cümle cümle dinlenilmiş ve noktalama işaretleri bulunmayan metne noktalama işaretleri de konulmuştur. İşaretlemeden sonraki okuma çalışmasında; bir cümle seslendirildikten sonra sesli kitap kaydı durdurulmuş; seslendirmede olduğu gibi kesme ve noktalama işaretlerine dikkat edilerek öğrenciden cümleyi tekrar okuması istenmiştir. Yapılan okumada öğrenci, cümledeki tonlama ve vurgulamaları tam olarak yansıtamadıysa bir diğer öğrenciye okutturulmuştur. Daha sonra diğer cümleler için kayıt yürütülmüş ve bu şekilde bütün metin tamamlanmıştır. Uygulama günde 1 saat olmak üzere 24 gün devam etmiştir. Çalışma boyunca ölçümler ön test, Ara test 1, ara test 2 ve son test olarak yapılmıştır.

Araştırma boyunca kullanılan metinler 2010-2011 öğretim yılında Afyonkarahisar ilindeki ilköğretim okullarındaki Türkçe derslerinde okutulmayan farklı yayınevlerine ait ve Milli Eğitim Bakanlığı'nın onayı olan ders kitaplarından (Çanakçı ve diğerleri, 2008; Gültekin ve Pekdemir, 2010; Öz ve Öz, 2010) seçilmiştir. Kullanılan metinlerin denkliğini sağlamak için olabildiğince özen gösterilmiş; metinler uygulanmadan önce Türkçe ve illk okuma-yazma öğretimi alanında uzman öğretim üyelerinin görüşüne sunulmuş ve kabul gördükten sonra uygulanmıştır. Bunun nedeni ise yapılan ölçme işleminde metin güçlüğünü denkleştirmenin ölçme işlemini daha güçlü hale getirmesidir (Deno, 2003). Bu tür çalışmalarda metinlerin türleri ve kullanımı konusunda değişik uygulamalar bulunmaktadır. Bazı araştırmalarda metin, aynı okuma parçasının değişik bölümlerinden (Dowhower, 1987); bazılarında ise aynı tür, birbirine denk, fakat farklı metinler kullanılmak suretiyle testler uygulanmıştır (Hiebert, 2005). Ön test, ara testler ve son test için müstakil gün belirlenmiş ve uygulanmıştır. Uygulamanın yapıldığı günlerde ise herhangi bir test yapılmamıştır.

\section{Verilerin analizi}

Illk aşamada, okuma hızı ve doğru okuma ile ilgili veriler toplanmış ve analiz edilmiştir. Bunun için bir dakikada doğru okunan kelime sayısı "Toplam okunan kelime sayısı - yapılan hata= doğru okunan kelime sayısı" şeklinde hesaplanmıştır (Deeney, 2010; Fuchs, Fuchs, Hosp ve Jenkins, 2001; Walpole ve McKenna, 2007). Okuma doğruluğu için “(doğru okunan kelime sayısı / okunan kelime sayısı) x 100 = doğru okuma yüzdesi" hesaplanmıştır. Doğru okuma yüzdesi, akıcı okumanın niteliği ve anlama ile doğrudan ilişkili olup akıcı okumanın ölçülmesinde bir boyut olarak değerlendirilmektedir 
(Daane, Campbell, Grigg, Goodman ve Oranje, 2005; Dowhower, 1991; Hudson ve diğerleri, 2005; Valencia ve diğerleri, 2010). Doğru okuma için sesli okuma hatalarının değerlendirilmesinde Akyol (2006:237) tarafından, Ekwall ve Shanker'den (1988) uyarlanan Yanlış Analiz Envanteri kullanılmıştır. Bu envantere göre, okuma esnasında atlayıp geçmeler, eklemeler, beş saniye içinde okuyamayan öğrenciye öğretmen tarafından verilen ipuçları, yanlış okumalar, ters çevirmeler ve tekrarlar okuma hataları olarak belirlenmiştir. Üçüncü aşamada, öğrencilerin prozodi düzeylerini belirlemek için "Prozodik Okuma Ölçeği” kullanılmıştır. Keskin ve Baştuğ (2011) tarafından geliştirilen bu ölçek prozodiyi bütün boyutları ile ölçmeyi amaçlamaktadır. Ölçek sesli okumada, tonlama, vurgulama, anlam üniteleri ile okuma, metindeki duyguyu yansıtarak okuma, okuma ritmi ve ses özellikleri gibi temel boyutları, ölçülecek unsurlar olarak dikkate almaktadır. Ölçeğin kapsam geçerliliği için uzman görüşüne başvurulmuştur. Ölçeğin yapı geçerliliği KMO=.97 ve Barlett analizi $(p=.00 ;<.01)^{\prime}$ dir. Cronbach's Alpha değeri ise 0.981 'dir. Bu değer $0.80^{\prime}$ in üzerindedir ve güvenirliğin yüksek bir tutarlılık göstergesi olarak kabul edilmektedir (Ho, 2006; Rathvon, 2004).

Grup büyüklüğünün 15 ve altı olduğu (Büyüköztürk, 2008) ve evrenin dağılım yapısının tam olarak bilinemediği durumlarda nonparametrik testlerin kullanılması önerilmektedir (Cohen ve diğerleri, 2007:415). Çalışmada tekrarlı ölçümler bulunması nedeniyle Friedman testi kullanılmış ve anlamlılık düzeyi .01 olarak alınmıştır. Friedman Testi'n de anlamlı çıkan sonuçlar için Nemenyi çoklu karşılaştırma testi uygulanmış ve Bonferroni düzeltmesi $(.01 / 6, p=.0017)$ yapılmıştır (Rubin ve Babbie, 2011:564).

\section{Bulgular}

Yapılandırılmış okuma yönteminin, dördüncü sınıf öğrencilerinin hızlı, doğru ve prozodik okuma becerilerini geliştirmede etkisini belirlemeye yönelik yapılan aralıklı ölçümler Friedman testi ile analiz edilmiş ve sonuçlar Tablo 1-6' da verilmiştir.

Tablo 1. Deney Öncesi, Ara Test1, Ara Test2 ve Deney Sonrası Yapılandırılmış Okuma Grubunun Okuma Hızı Puanları Friedman Testi Sonuçları

\begin{tabular}{llccccc}
\hline Tekrarlı Ölçümler & $\mathrm{n}$ & $\overline{\mathrm{x}}$ & $\mathrm{S}$ & Sıra Ortalaması & $\chi^{2}$ & $\mathrm{p}$ \\
\hline Ön Test & 9 & 52,88 & 8,52 & 1,00 & 22,73 &, $000^{*}$ \\
\hline Ara Test 1 & 9 & 76,33 & 1,64 & 3,00 & & \\
\hline Ara Test 2 & 9 & 64,66 & 14,23 & 2,22 & \\
\hline Son Test & 9 & 82,22 & 13,90 & 3,78 & \\
\hline * $<0.01$ & & & &
\end{tabular}

Analiz sonuçları, deney grubundaki öğrencilerin, ön test, ara test1, ara test2 ve son test okuma hızı puanları arasında anlamlı bir fark olduğunu göstermektedir $\left(\chi^{2}=22.73, p<.01\right)$. Farkın hangi ölçme 
aralığından kaynaklandığını belirlemeye yönelik post-hoc karşılaştırma sonuçları Tablo 2'de verilmiştir.

Tablo 2. Deney Öncesi, Ara Test1, Ara Test2 ve Deney Sonrası Yapılandırılmış Okuma Grubunun Okuma Hızı puanlarına ilişkin Nemenyi Testi Sonuçları

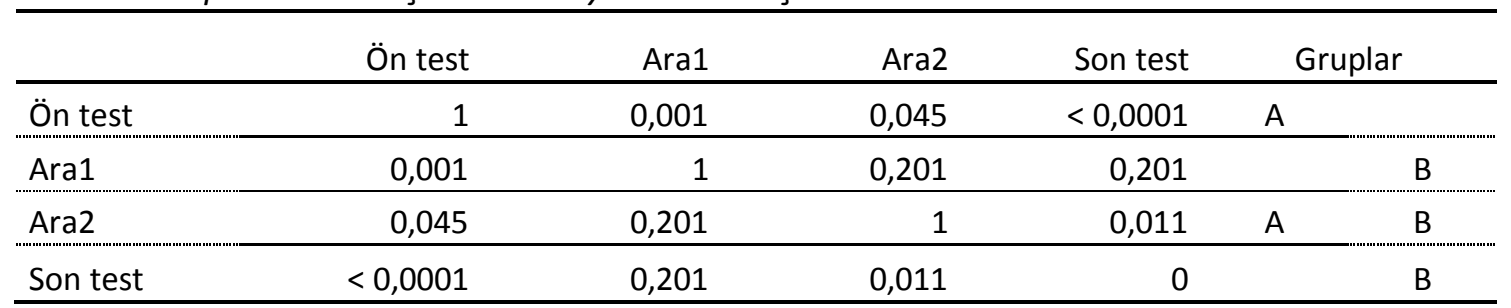

Analiz sonuçları anlamlı farklılı̆ın, araştırmaya katılan öğrencilerin ön test-ara test1 ile ön test-son test puanları arasında olduğunu göstermektedir. Diğer testler arasında anlamlı bir farklılık görülmemiştir. Gruplar arası farklılaşmalara bakıldığında da farklılı̆̆ı yaratan testlerin ön test, ara test1 ve son test olduğu görülmektedir. Bu verilere göre okuma hızı için; yapılandırılmış yöntem ile hızlı gelişen ancak kararlı bir yapıya kavuşması için belli bir süreye ihtiyaç duyan bir beceri olduğu söylenebilir.

Tablo 3. Deney Öncesi, Ara Test1, Ara Test2 ve Deney Sonrası Yapılandırılmış Okuma Grubunun Doğru Okuma Puanları Friedman Testi Sonuçları

\begin{tabular}{lcccccc}
\hline Tekrarlı Ölçümler & $\mathrm{n}$ & $\overline{\mathrm{x}}$ & $\mathrm{S}$ & Sıra Ortalaması & $\chi^{2}$ & $\mathrm{p}$ \\
\hline Ön Test & 9 & 85,47 & 5,73 & 1,44 & 15,80 &, $001^{*}$ \\
\hline Ara Test 1 & 9 & 92,34 & 3,52 & 2,67 & \\
\hline Ara Test 2 & 9 & 91,03 & 5,36 & 2,09 & \\
\hline Son Test & 9 & 95,48 & 2,62 & 3,78 & \\
\hline
\end{tabular}

$* \mathrm{p}<0.01$

Analiz sonuçları, deney grubundaki öğrencilerin, ön test, ara test1, ara test2 ve son test doğru okuma puanları arasında anlamlı bir fark olduğunu göstermektedir $\left(\chi^{2}=15.80, p<.01\right)$. Farkın hangi ölçme aralığından kaynaklandığını belirlemeye yönelik post-hoc karşılaştırma sonuçları Tablo 4'de verilmiştir.

Tablo 4. Deney Öncesi, Ara Test1, Ara Test2 ve Deney Sonrası Yapılandırılmış Okuma Grubunun Doğru Okuma puanlarına ilişkin Nemenyi Testi Sonuçları

\begin{tabular}{lrrrrrr} 
& Ön test & Ara1 & Ara2 & Son test & Gruplar \\
\hline Ön test & 1 & 0,045 & 0,273 & 0,000 & A & \\
\hline Ara1 & 0,045 & 1 & 0,361 & 0,068 & A & B \\
\hline Ara2 & 0,273 & 0,361 & 1 & 0,006 & A & B \\
Son test & 0,000 & 0,068 & 0,006 & 0 & B \\
\hline
\end{tabular}


Analiz sonuçları anlamlı farklılığın, araştırmaya katılan öğrencilerin ön test-son test puanları arasında olduğunu göstermektedir. Diğer testler arasında anlamlı bir farklılık görülmemiştir. Gruplar sütununda da görüldüğü üzere anlamlı farklılaşma sadece ön test ve son test puanları arasında gerçekleşmiştir. Bu veriler, yapılandırılmış okuma yönteminin, doğru okuma becerisi üzerinde kısa dönemlerden ziyade daha uzun uygulama dönemlerinde anlamlı değişikliklere yol açıı̆̆ı şeklinde yorumlanabilir.

Tablo 5. Deney Öncesi, Ara Test1, Ara Test2 ve Deney Sonrası Yapılandırılmış Okuma Grubunun Prozodi Puanları Friedman Testi Sonuçları

\begin{tabular}{llccccc}
\hline Tekrarlı Ölçümler & $\mathrm{n}$ & $\overline{\mathrm{x}}$ & $\mathrm{S}$ & Sıra Ortalaması & $\chi^{2}$ & $\mathrm{p}$ \\
\hline Ön Test & 9 & 22,55 & 5,10 & 1,39 & 19,22 &, $000^{*}$ \\
\hline Ara Test 1 & 9 & 23,44 & 4,79 & 1,83 & \\
\hline Ara Test 2 & 9 & 28,44 & 6,38 & 3,06 & \\
\hline Son Test & 9 & 31,77 & 6,85 & 3,72 & \\
\hline
\end{tabular}

${ }^{*} p<0.01$

Tablo 5'deki analiz sonuçları, deney grubundaki öğrencilerin, ön test, ara test1, ara test2 ve son test prozodi puanları arasında anlamlı bir fark olduğunu göstermektedir $\left(\chi^{2}=19.22, p<.01\right)$. Farkın hangi ölçme aralığından kaynaklandığını belirlemeye yönelik post-hoc karşılaştırma sonuçları Tablo 6'da verilmiştir.

Tablo 6. Deney Öncesi, Ara Test1, Ara Test2 ve Deney Sonrası Yapılandırılmış Okuma Grubunun Prozodi puanlarına iliş̧kin Nemenyi Testi Sonuçları

\begin{tabular}{|c|c|c|c|c|c|c|}
\hline & Ön test & Ara1 & Ara2 & Son test & \multicolumn{2}{|c|}{ Gruplar } \\
\hline Ön test & 1 & 0,465 & 0,006 & 0,000 & A & \\
\hline Ara1 & 0,465 & 1 & 0,045 & 0,002 & A & $B$ \\
\hline Ara2 & 0,006 & 0,045 & 1 & 0,273 & $\mathrm{~A}$ & $B$ \\
\hline Son test & 0,000 & 0,002 & 0,273 & 0 & & B \\
\hline
\end{tabular}

Tablo 6'da Nemenyi testi sonuçlarına göre anlamlı farklıığın, araştırmaya katılan öğrencilerin ön test - son test puanları arasında olduğu görülmektedir. Gruplar sütununda da görüldüğü üzere anlamlı farklılaşma sadece ön test ve son test verileri arasında gerçekleşmiştir. Bu veriler, yapılandırılmış okuma yönteminin, prozodi becerisi üzerinde kısa dönemlerden ziyade daha uzun uygulama dönemlerinde anlamlı değişikliklere yol açtığı şeklinde yorumlanabilir.

\section{Tartışma ve Sonuç}

$\mathrm{Bu}$ çalışma ile yapılandırılmış okuma yönteminin akıcı okuma becerisini yeterince kazanamamış ilköğretim dördüncü sınıf öğrencilerinin, okuma hızı, doğru okuma ve prozodik okuma 
becerileri üzerindeki etkisinin araştıııması amaçlanmıştır. Bu amaca yönelik aralıklı olarak deney grubunun gelişimi ölçülmüştür. Aralıklı ölçüm sonuçlarına göre yapılandırılmış okuma yöntemi okuma hızı üzerinde Ön Test - Ara Test 1 ve Ön Test - Son Test aralıklarında anlamlı farklılıklar oluşturmuştur. Elde edilen verilere göre yapılandııılmış okuma yönteminin, akıcı okuma becerileri yönünden endişe düzeyinde olan öğrencilerin, bu becerilerini geliştirmede etkili olduğunu söylemek mümkündür.

Doğru okuma puanları yapılandırılmış okuma yöntemi aralıklı ölçme dönemlerinde anlamlı bir değişim göstermemesine rağmen en uzun ölçme aralığı olan ön test-son test aralığında anlamlı olarak değişmiştir. Aynı şekilde prozodi puanları da en uzun ölçme aralığı olan ön test-son test aralığında anlamlı olarak değişmiştir. Yapılandırımış okuma yöntemi hem doğru okuma hem de prozodi becerileri üzerinde kısa dönemlerden ziyade daha uzun dönemlerde etkili olmuştur. Bu durumda yapılandırılmış okuma yönteminin okuma hızı üzerinde oldukça etkili olduğu ve bu etkinin sürdürülebilir olması için de belli bir süreye ihtiyaç duyulduğu düşünülebilir.

Yapılandırımış okuma yöntemi temelde iki bileşen üzerine kurgulanmıştır. Bunlar prozodik etkin modelleme ve anlam üniteleri ile okumadır. Bu çalışmada ses modellemesi doğrudan seslendirilmiş kitaplar yoluyla sağlanmıştır. Etkin model desteğinin sunulduğu çalışmalarda benzer uygulamalar yapılmasına rağmen hepsi de farklı şekillerde gerçekleştirilmiştir (Dowhower, 1991; Morra ve Tracey, 2006; Snow, Coots ve Smith, 1982). Dowhower (1991) okuma güçlüğü bulunan ikinci sınıf öğrencileri üzerinde uygun duraklama ve anlam grupları ile okumayı içeren bir çalışmada oldukça etkili sonuçlar elde etmiştir. Bu araştırmada da anlam üniteleri ile yapılan okuma etkinlikleri sonucunda yapılandırımış okuma yöntemi hem prozodi hem de okuma hızı üzerinde en etkili yöntem olmuştur. Uygulama aşamasında duraklama yerlerini "/ " işareti ile işaretlemek öğrenciye kolaylık sağlamaktadır. Bu yöntem anlam üniteleri ile okumayı kolaylaştırmaktadır. Çünkü bu araştırmanın ilk uygulama derslerinde öğrenciler cümlenin anlam ünitesi oluşturan bölümlerini tespitte zorlanmışlardır. Ancak "/" işareti ile işaretlemelerin yapılmasından sonra bu beceri diğer okuma uygulamalarına da transfer edilmiştir. Uygulamanın son derslerine doğru öğrenciler işaretlemeleri büyük bir oranda doğru şekilde yapmışlardır. Aynı şekilde bu uygulamanın etkililiği önceki araştırma bulguları (Dowhower, 1991; Hudson ve diğerleri, 2005; Nichols, Rupley ve Rasinski, 2009) ile de örtüşmektedir.

Araştırmadan elde edilen sonuçlara bakıldığında Yapılandırılmış okuma yönteminin, öğrencilerin okuma hızı, doğru okuma ve prozodi becerileri üzerinde etkili olduğu görülmüştür. Daha önceki çalışmalara bakıldığında (Dowhower, 1991; Morra ve Tracey, 2006; Snow ve diğerleri, 1982) öğrencilerin prozodi puanlarının yükseldiği görülmektedir. Bu durumu ise sesli okumadaki prozodinin etkin modelleme sayesinde gelişebildiğine dayanak olarak göstermek mümkündür. Bu bulguları kısmen destekleyen sonuçları, Young ve diğerleri'nin (1996) çalışmasında da görülebilir. Ancak, Young ve diğerleri (1996) prozodik modelleme ve yoğun okuma yapılan gruplarda okuma becerisinin genel 
olarak ilerlediğini söylemekle birlikte bu kazanımın prozodik modellemeden mi yoksa yoğun okumadan mı kaynaklandığını açıklığa kavuşturamamışlardır. Yukarıda sözü edilen önceki araştırmalarda ve bu araştırmada etkin prozodik modellemenin prozodi üzerindeki etkisi daha belirgin hale gelmiştir. Diğer taraftan, elde edilen bu sonuçlar bu konuda daha fazla araştırmaya gereksinim olduğunu ve farklı değişkenlerle birlikte, okumada hız, doğruluk ve prozodi arasındaki nedenselliğin çözümlenmesi gerektiğini de ortaya koymaktadır.

Benzer çalışmaların daha farklı gruplarla ya da yapılandırılmış yönteme ek tekniklerin dâhil edilmesiyle, özel gereksinime ihtiyaç duyan öğrencilerin akıcı okuma becerilerinin iyileştirilmesi çalışmalarının devam etmesi bu çalışmanın temel önerilerinden biridir. Bir diğeri öneri olarak ise sesli kitaplar yoluyla cümle cümle işitsel/prozodik modelleme yerine kısa paragraflarla benzer çalışmaların hem özel gereksinime muhtaç hem de normal öğrencilerle yapılması ve hangi grupta ne derece ilerlenebildiğinin karşılaştırılmasıdır.

\section{Kaynakça}

Akyol, H. (2006). Türkçe ilk okuma yazma öğretimi. Ankara: Pegem A Yayınclık Ltd. Şti.

Büyüköztürk, Ş. (2008). Sosyal bilimler için veri analizi el kitabı: Istatistik, araştırma deseni, spss uygulamaları ve yorum. Ankara: Pegem Akademi.

Chall, J. S., Jacobs, V. A. ve Baldwin, L. E. (1991). The reading crisis: Why poor children fall behind. Massachusetts: Harvard University Press.

Cohen, L., Manion, L. ve Morrison, K. (2007). Research methods in education. New York: Routledge.

Çanakçı, H., Özaykut, S., Taşdemir, K., Yardımcı, S. ve Yetimoğlu, E. B. (2008). Illköğretim türkçe 4 ders kitabı. İstanbul: Bediralp Matbaacilı.

Daane, M. C., Campbell, J. R., Grigg, W. S., Goodman, M. J. ve Oranje, A. (2005). Fourth-grade students reading aloud: Naep 2002 special study of oral reading. Washington, DC: U.S. Department of Education. Institute of Education Sciences, National Center for Education Statistics.

Deeney, T. A. (2010). One-minute fluency measures: Mixed messages in asssessment and instruction. Reading Teacher, 63(6), 440-450.

Deno, S. L. (2003). Developments in curriculum-based measurement. Journal of Special Education, 37(3), 184192.

Dowhower, S. L. (1987). Effects of repeated reading on second-grade transitional readers' fluency and comprehension. Reading Research Quarterly, 22(4), 389-406.

Dowhower, S. L. (1991). Speaking of prosody: Fluency's unattended bedfellow. Theory Into Practice, 30(3), 165175.

Ehri, L. C. ve McCormick, S. (1998). Phases of word learning: Implications for instruction with delayed and disabled readers. Reading \& Writing Quarterly, 14(2), 135.

Ekwall, E. E. ve Shanker, J. L. (1988). Diagnosis and remediation of the disabled reader (3 ed.): Allyn and Bacon.

Fuchs, L. S., Fuchs, D., Hosp, M. K. ve Jenkins, J. R. (2001). Oral reading fluency as an indicator of reading competence: A theoretical, empirical, and historical analysis. Scientific Studies of Reading, 5(3), 239 256.

Gültekin, i. ve Pekdemir, A. Z. (2010). Illköğretim 4. Sınıf türkçe ders kitabı. İstanbul: Kelebek Yayıncılık.

Harris, A. J. ve Sipay, E. R. (1990). How to increase reading ability: A guide to developmental \& remedial methods. New York: Longman.

Harris, T. L. ve Hodges, R. E. (1995). The literacy dictionary : The vocabulary of reading and writing. Newark, Del.: International Reading Association.

Hiebert, E. H. (2005). The effects of text difficulty on second graders' fluency development. Reading Psychology, 26(2), 183-209.

Ho, R. (2006). Handbook of univariate and multivariate data analysis and interpretation with spss. Boca Raton FL: Taylor \& Francis Group. 
Hudson, R. F., Lane, H. B. ve Pullen, P. C. (2005). Reading fluency assessment and instruction: What, why, and how? Reading Teacher, 58(8), 702-714.

Keskin, H. K. ve Baştuğ, M. (2011). ilköğretim dördüncü sınıf öğrencilerinin sesli okuma ve konuşma prozodileri arasındaki ilişkinin incelenmesi. Paper presented at the 10. Sınıf Öğretmenliği Eğitimi Sempozyumu. 57 Mayıs 2011. Sivas.

Kuhn, M. R. (2005). A comparative study of small group fluency instruction. Reading Psychology, 26(2), 127 146.

Kuhn, M. R., Schwanenflugel, P. J., Meisinger, E. B., Levy, B. A. ve Rasinski, T. V. (2010). Aligning theory and assessment of reading fluency: Automaticity, prosody, and definitions of fluency. Reading Research Quarterly, 45(2), 230-251.

Logan, G. D. (1997). Automaticity and reading: Perspectives from the instance theory of automatization. Reading \& Writing Quarterly, 13(2), 123-146.

Milli Eğitim Bakanlığı. (2011). Eğitim teknolojileri genel müdürlüğü-100 temel eser. from Web: http://yuzeser.meb.gov.tr/ adresinden 01.02.2011 tarihinde alınmıştır.

Morra, J. ve Tracey, D. H. (2006). The impact of multiple fluency interventions on a single subject. Reading Horizons, 47(2), 175-175-198.

Morrow, L. M., Kuhn, M. R. ve Schwanenflugel, P. J. (2006). The family fluency program. Reading Teacher, 60(4), 322-333.

National Reading Panel. (2000). Teaching children to read: An evidence-based assessment of the scientific research literature on reading and its implications for reading instruction. National Reading Panel.

Nichols, W. D., Rupley, W. H. ve Rasinski, T. (2009). Fluency in learning to read for meaning: Going beyond repeated readings. Literacy Research and Instruction, 48(1), 1 - 13.

Öz, E. ve Öz, S. (2010). ilköğretim 4. Sınıf türkçe ders kitabı. İzmir: Top Yayıncılık.

Özbay, M. ve Melanlıoğlu, D. (2008). Türkçe eğitiminde kelime hazinesinin önemi. Yüzüncü Yıl Üniversitesi, Eğitim Fakültesi Dergisi, 5(1), 30-45.

Rashotte, C. A. ve Torgesen, J. K. (1985). Repeated reading and reading fluency in learning disabled children. Reading Research Quarterly, 20(2), 180-188.

Rasinski, T. (2010). The fluent reader. New York: Scholastic.

Rathvon, N. (2004). Early reading assessment. New York: A Division of Guilford Publications, Inc.

Rubin, A. ve Babbie, E. R. (2011). Research methods for social work (Seventh ed.). Belmont, CA: Brooks/Cole, Cengage Learning.

Samuels, S. J. (1979). The method of repeated readings. Reading Teacher, 32, 403-408.

Samuels, S. J. (2006a). Looking backward: Reflection on a carrier in reading. Journal of Literacy Research, 38(3), 327-344.

Samuels, S. J. (2006b). Reading fluency: Its past, present, and future. In T. V. Rasinski, C. L. Z. Blachowicz ve K. Lems (Eds.), Fluency instruction : Research-based best practices (pp. xvii, 302 p.). New York ; London: The Guilford Press Inc.

Schrauben, J. E. (2010). Prosody's contribution to fluency: An examination of the theory of automatic information processing. Reading Psychology, 31(1), 82 - 92.

Schreiber, P. A. (1991). Understanding prosody's role in reading acquisition. Theory Into Practice, 30(3), 158.

Schwanenflugel, P. J., Kuhn, M. R., Morris, R. D., Morrow, L. M., Meisinger, E. B., Woo, D. G. ve diğerleri. (2009). Insights into fluency instruction: Short- and long-term effects of two reading programs Literacy Research and Instruction, 48(4), 318-336.

Snow, D. P., Coots, J. H. ve Smith, K. (1982). Speech prosody and children's perception of sentence organization Southwest Regional Laboratory technical note; no. TN 2-82/34, ERIC Document Reproduction service No. 222890.

Stahl, S. A. ve Kuhn, M. R. (2002). Making it sound like language: Developing fluency. Reading Teacher, 55(6), 582-584.

Valencia, S. W., Smith, A. T., Reece, A. M., Li, M., Wixson, K. K. ve Newman, H. (2010). Oral reading fluency assessment: Issues of construct, criterion, and consequential validity. Reading Research Quarterly, 45(3), 270-291.

Walpole, S. ve McKenna, M. C. (2007). Differentiated reading instruction. New York: The Guilford Press A Division of Guilford Publications, Inc.

Wolf, M. ve Katzir-Cohen, T. (2001). Reading fluency and its intervention. Scientific Studies of Reading, 5(3), 211-239.

Yıldız, M., Yıldırım, K., Ateş, S. ve Çetinkaya, Ç. (2009). An evaluation of the oral reading fluency of 4th graders with respect to prosodic characteristic International Journal of Human Sciences, 6(1), 353-360. 
Young, A. R., Bowers, P. G. ve MacKinnon, G. E. (1996). Effects of prosodic modeling and repeated reading on poor readers' fluency and comprehension. Applied Psycholinguistics, 17(1), 59-84.

Zutell, J., Donelson, R., Bevans, J. ve Todt, P. (2006). Building a focus on oral reading fluency into individual instruction for struggling readers. In T. Rasinski, C. Blachowicz ve K. Lems (Eds.), Fluency instruction: Research-based best practices. New York: The Guilford Press Inc.

Zutell, J. ve Rasinski, T. (1991). Training teachers to attend to their student's oral reading fluency. Theory Into Practice, 30(3), 211. 